\title{
Emergency Department Admissions for Dental \& Oral Health Concerns in Rural Northwestern Pennsylvania
}

\author{
Matthew Zaborowski, Rebecca Dawson \\ Allegheny College, Meadville, PA, USA \\ Email: zaborowskim@allegheny.edu, rdawson@allegheny.edu
}

Received 8 January 2016; accepted 28 March 2016; published 31 March 2016

Copyright (C) 2016 by authors and Scientific Research Publishing Inc.

This work is licensed under the Creative Commons Attribution International License (CC BY). http://creativecommons.org/licenses/by/4.0/

\section{(c) (i) Open Access}

\begin{abstract}
Background: Oral health emergency department (ED) visits are increasing nationally. This increase in ED admissions is an indicator that preventative dental and oral healthcare practices are not being utilized. Methods: Data was obtained from the Meadville Medical Center. Fourteen ICD-9 codes for dental and oral health admissions over 10 years were categorized and analyzed. Data was graphed to illustrate trends over time and the chi-square test of independence was used to determine associations between admissions types and demographic characteristics. Results: ED admissions for dental and oral health issues were most common among individuals age 19 - 38 years. Most individuals admitted to the ED for these concerns paid with private medical insurance or were uninsured. The categorization of ICD-9 codes allowed us to see that ED use for structural and soft-issues decreased at the end of the decade under study. However, admissions for infections and dental caries increased over time. Conclusions: The opening of a free dental clinic in 2011 might be associated with the decrease in overall admissions for dental and oral health concerns as well as soft tissue and structural admissions. The increase in ED admissions for dental caries and infections illustrates that more affordable and preventative dental and oral health care and education are need.
\end{abstract}

\section{Keywords}

Community Health, Oral Health, Emergency Department Admissions

\section{Introduction}

With increasing costs of oral healthcare and lower rates of individuals with dental insurance, the prevalence of 
hospital emergency departments (ED) admissions for dental and other oral health concerns, such as dental caries, gum infections, gum disease, periodontal disease, and oral cancer, among others, is increasing in the United States [1]-[4]. According to the American Dental Association (ADA), 80\% of dental and other oral health ED admissions can be prevented [5]-[8]. In addition, ED admissions for these types of concerns have doubled from 1.1 million in 2000 to 2.2 million in 2012 with an estimated price for each ED admission being three times more than a typical dental visit for toothaches, tooth sensitivity, dental caries that caused infections and other serious complications. The cost of ED admissions for dental and other oral health issues is approximately $\$ 1.5$ billion USD annually [5]-[8].

The Agency for Health Care Research and Quality in addition to the Healthcare Cost and Utilization Project both found that dental and other oral health ED admissions were nearly four times higher among patients living in poorer communities compared to communities where the socioeconomic status (SES) of residents was higher [9]-[12]. In rural areas of the United States, lower SES levels combined with an aging population, shortages of providers, and inadequate preventative services have resulted in ED admissions rates for dental and other oral health issues that are growing exponentially [10] [12].

The Meadville Medical Center is a 249-bed non-profit community hospital located in northwestern Pennsylvania. The population served by the Meadville Medical Center includes the majority of residents in Crawford County, PA ( 58,000 individuals). Crawford County is a rural community located 90 miles north of Pittsburgh, PA and 40 miles south of Erie, PA. Approximately 17\% of the population in Crawford County lives below the poverty line; less than $20 \%$ of adults have completed a Bachelor's degree in spite of the fact that $87 \%$ have completed high school; and nearly $18 \%$ of adults are senior citizens [13]. The city of Meadville is home to approximately 13,000 residents as well as the Meadville Medical Center, Allegheny College, and city, county, and state governmental offices [14]. However, more than a quarter of the city residents are considered impoverished [14].

At the Meadville Medical Center, there are approximately 35,000 ED admissions each year; informal observations from the ED physicians and hospital administrators indicate that dental and other oral health admissions are prevalent and increasing in frequency. Results from an analysis of Ed admissions can be used to understand the patterns of admissions and lead to the creation of policies and programs to improve the dental and oral health of individuals living in the Meadville area [15]-[18]. Our research aims to determine the prevalence of dental and other oral health ED admissions as well as patterns of patient demographics for those seeking care for dental and oral health concerns in the Meadville Medical Center ED from 2004-2014. We intend to use the results to design and implement policies and programs to improve dental and oral health locally. Additionally, we hope that our novel categorization of ICD-9 codes can be used by other communities to evaluate ED admissions for dental and oral health concerns with a new level of specificity.

\section{Methods}

Data. The Allegheny College and Meadville Medical Center Institutional Review Boards approved this study. Upon approval, de-identified ED admission records from the Meadville Medical Center between January 1, 2004 and December 31, 2014 were obtained by the research team. Specifically, data for each ED admissions was collected, including ICD-9 code and diagnosis name; date, time, and year of admittance; age at admittance; date of birth; gender; race; and payment method.

Variables. We extracted all of the dental/oral health complaints data for our analyses using the ICD-9 code for each diagnosis. The dental/oral health data was further sub-categorized into 6 categories: [1] tooth \& supporting structure complications; [2] dental caries; [3] infection; [3] unspecified diseases of the soft tissue; [4] injury; and [5] inflammation of gland (Box 1). Inflammation of the gland (category 6) admissions was excluded prior to statistical analysis. We decided that these admissions, though originating in/near the mouth, were not necessarily a dental or oral health concern. Additionally, we felt the number admissions for these ICD-9 codes were too small for analyses $(n=70)$.

The data was stratified by age, gender, race, payment method, quarter and year visited. Age was categorized into four groups: 0 - 18; 19 - 38; 39 - 58; 59+. Race was grouped into three categories: Caucasian, African American, and other. To analyze patterns of seasonality in admissions, we grouped admissions date by yearly quarter: January-March; April-June; July-September; and October-December. Payment methods were divided into six categories: private medical insurance, auto insurance, medical assistance, Medicare, workers compensation 
Box 1. Categorization of ICD-9 codes for Dental and Oral Health Admissions to the ED at the Meadville Medical Center (2004-2014).

\begin{tabular}{|c|c|c|}
\hline Categories & ICD-9-CM & $\mathrm{N}$ \\
\hline \multirow{4}{*}{$\begin{array}{l}\text { [1] Tooth \& supporting } \\
\text { structure complications } \\
(\mathrm{n}=7265)\end{array}$} & ICD-9-CM Code: 520.6 “Disturbances in tooth eruption” & 73 \\
\hline & ICD-9-CM Code: 525.9 “Unspecified disorder of the teeth and supporting structures” & 6974 \\
\hline & ICD-9-CM Code: 526.9 “Unspecified disease of the jaws” & 147 \\
\hline & ICD-9-CM Code: 522.4 “Acute apical periodontitis of pulpal origin” & 71 \\
\hline \multirow{2}{*}{$\begin{array}{l}\text { [2] Dental caries } \\
(\mathrm{n}=1202)\end{array}$} & ICD-9-CM Code: 521.00 “Dental caries, unspecified” & 1093 \\
\hline & ICD-9-CM Code: 521.09 “Other dental caries” & 109 \\
\hline \multirow{3}{*}{$\begin{array}{l}\text { [3] Infection } \\
(\mathrm{n}=1140)\end{array}$} & ICD-9-CM Code: 522.5 “Periapical abscess without sinus” & 925 \\
\hline & ICD-9-CM Code: 112.0 “Candidiasis of mouth” & 136 \\
\hline & ICD-9-CM Code: 054.2 “Herpetic gingivostomatitis” & 79 \\
\hline $\begin{array}{l}\text { [3] Unspecified diseases } \\
\text { of the soft tissue } \\
(n=740)\end{array}$ & ICD-9-CM Code: 528.9 “Other and unspecified diseases of the oral soft tissues” & 740 \\
\hline \multirow{3}{*}{ [4] Injury $(n=267)$} & ICD-9-CM Code: 873.60 “Open wound of mouth unspecified site, without mention of complication & 77 \\
\hline & $\begin{array}{l}\text { ICD-9-CM Code: } 873.63 \text { “Open wound of tooth (broken) (fractured) (due to trauma), } \\
\text { without mention of complication” }\end{array}$ & 117 \\
\hline & ICD 9-CM Code: 873.64 “Open wound of tongue and floor of mouth, without mention of complication” & 73 \\
\hline $\begin{array}{l}\text { [4] Inflammation of } \\
\text { Salivary Gland }(\mathrm{n}=86)\end{array}$ & ICD-9-CM Code: 527.2“Sialoadenitis” & 86 \\
\hline
\end{tabular}

insurance, and uninsured. The uninsured category included uninsured, self-pay, and unable to obtain insurance information.

Data Analyses. To determine changes over time for dental and oral health ED admissions, we plotted each admissions type by year. This resulted in a decade long (2004-2014) trend analysis. All other data analyses were done using Pearson's chi-square statistic, as all the data we analyzed was categorical. The data were organized in Microsoft Excel 2010. All statistical analyses were performed using SAS 9.4 University version software.

\section{Results}

The study sample consisted of 10,697 dental and other oral health admissions recorded in the Meadville Medical Center ED from 2004 to 2014. These 10,697 admissions accounted for 3.3\% of the total ED admission ( $\mathrm{n}=$ 324,170) in the Meadville Medical Center ED (2004-2014). An examination of the changes over time for all the ED admissions for dental and oral health concerns shows little change. Since 2011 the total number of admissions has decreased. A specific look at the categories of ICD-9 codes over time illustrates that structural concerns have increased from 2005 to 2010; and decreased by half between 2010-2014. Dental caries decreased through the decade until 2010. Since then there has been a linear increase in the rate of admissions to the ED for dental caries. Admissions for soft tissue concerns increased significantly between 2011-2013, but decreased between 2013-2014. Oral health related injuries have remained constant over the past decade (Figure 1).

The majority of patients admitted to the ED were 19 - 38 years of age followed by 39 - 58 years. The two most typical payment methods used were private medical insurance and uninsured (Table 1). Uninsured patients 


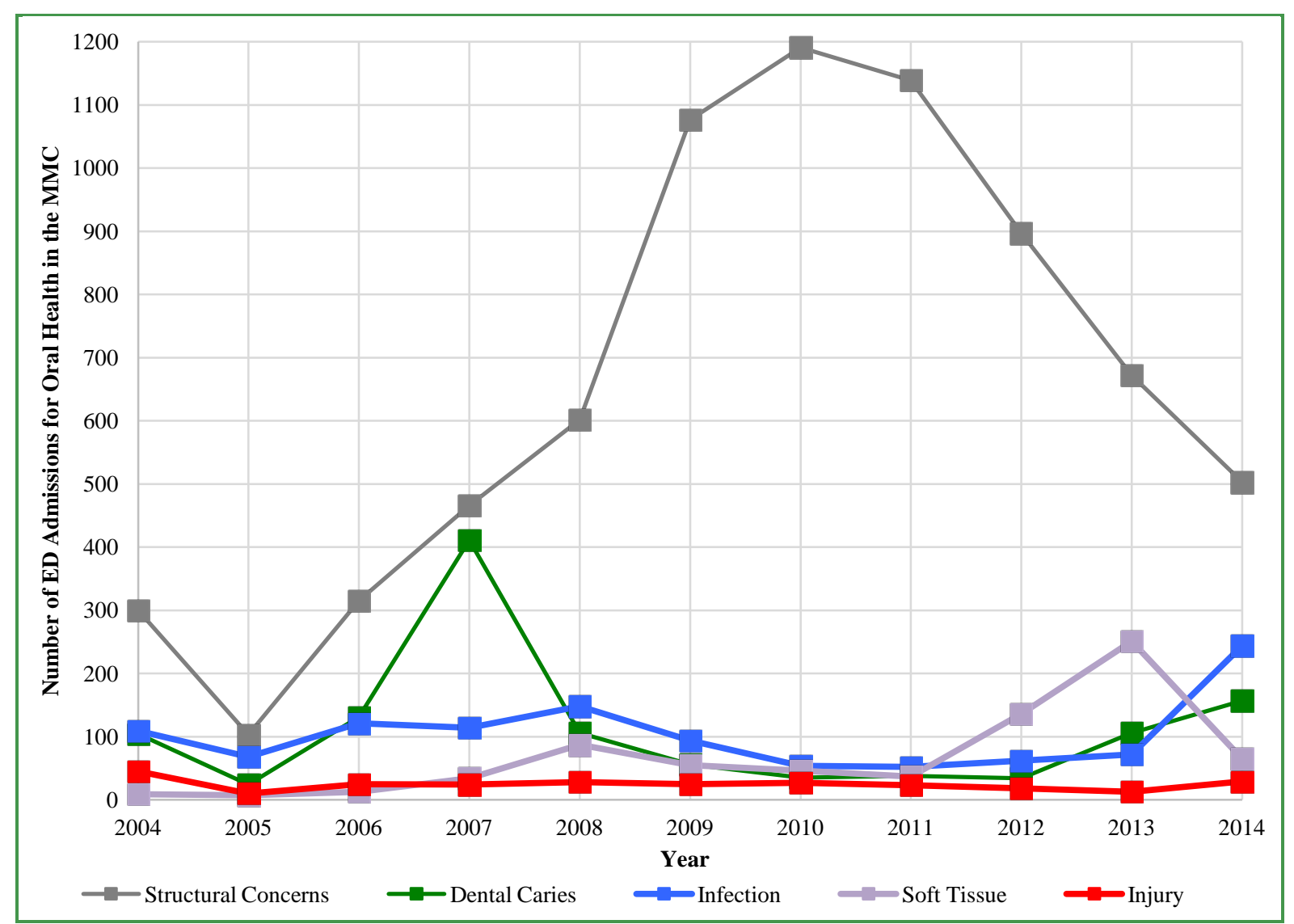

Figure 1. Trends over time of the total number of Dental \& Health ED Admissions data at the Meadville Medical Center (2004-2014).

most commonly used the ED for tooth and supporting structure concerns, accounting for $70 \%$ of the total admission under this payment method. Among those lacking medical insurance, those ages 19 - 38 years were the largest population (Table 2).

Dental and other oral health concerns consisted of 3.3\% of the total ED admission from 2004-2014. Six thousand nine hundred and seventy-four (6,974) admissions were for ICD-9 Code 525.9-Unspecified disorder of the teeth and supporting structures; this is the second most prevalent ICD-9 code reported in the Meadville Medical Center ED among all admissions (not just those related to dental and oral health) over the past decade. The data show that the majority of patients coming in for ICD-9 code 525.9 were those ages 19 - 38 and 39 - 58 . Despite a recent decrease in admissions for ICD-9 code 525.9, the highest prevalence of the code was found between 2009-2012 (Table 3).

\section{Discussion}

Our analysis of 10 years of admissions data at the Meadville Medical Center ED illustrates that the hospital has seen more than 1,000 admissions each year for dental and other oral health concerns. Trends in the type of admission varied throughout the decade: structural concerns increased throughout the first half of the decade and then deceased significantly during the second half. During the second half of the decade, admissions for infections and dental caries have increased. Despite significantly increasing in the middle of the decade, soft tissue admissions are currently declining (Figure 1). The majority of patients admitted to the Meadville Medical Center ED for dental and oral health reasons were aged 19 - 38 years. These patients primarily used private medical insurance or were uninsured (Table 1).

Our research is the first to document ED admissions for dental and oral health concerns within Pennsylvania. Our findings support national trends that shows ED admissions for dental and other oral health concerns are 
Table 1. Socio-demographic and admissions information for individuals admitted to the Meadville Medical Center ED for dental and oral health reasons by ICD-9 category (2004-2014).

\begin{tabular}{|c|c|c|c|c|c|c|}
\hline Characteristics & $\begin{array}{l}\text { Total Dental \& Oral } \\
\text { Health Admissions }\end{array}$ & $\begin{array}{c}\text { Tooth \& Support } \\
\text { Structure Concerns }\end{array}$ & Dental Caries & Infection & $\begin{array}{l}\text { Unspecified Diseases } \\
\text { of the Soft Tissue }\end{array}$ & Injury \\
\hline & N (column percent) & \multicolumn{5}{|c|}{$\mathrm{N}$ (row percent) } \\
\hline \multicolumn{7}{|l|}{ Sex } \\
\hline Male & 5215 (49.1) & 3534 (67.3) & $603(11.5)$ & $562(10.7)$ & $358(6.8)$ & $158(3.0)$ \\
\hline Female & 5397 (50.9) & 3731 (68.5) & $599(11.0)$ & $576(10.6)$ & $382(7.0)$ & $109(2.0)$ \\
\hline \multicolumn{7}{|l|}{ Race } \\
\hline Caucasian & $9826(92.5)$ & $6700(67.8)$ & $1119(11.3)$ & $1061(10.7)$ & $694(7.0)$ & $252(2.5)$ \\
\hline African American & $692(6.5)$ & $494(71.4)$ & 75 (10.8) & $72(10.4)$ & $39(5.6)$ & $12(1.7)$ \\
\hline Other & $92(1.0)$ & $49(74.2)$ & $3(4.6)$ & $4(6.1)$ & $6(9.1)$ & $3(4.6)$ \\
\hline \multicolumn{7}{|l|}{ Age } \\
\hline $0-18$ & $871(8.2)$ & $412(46.7)$ & $59(6.7)$ & $191(21.7)$ & $72(8.2)$ & $137(15.5)$ \\
\hline $19-38$ & 7608 (71.7) & $5485(72.0)$ & $911(12.0)$ & $629(8.3)$ & $491(6.44)$ & $92(1.2)$ \\
\hline $39-58$ & $1,844(17.4)$ & $1228(65.7)$ & $219(11.7)$ & $243(13.0)$ & $134(7.2)$ & $20(1.1)$ \\
\hline $59+$ & $289(2.7)$ & $140(43.1)$ & $13(4.0)$ & $75(23.1)$ & $43(13.2)$ & $18(5.6)$ \\
\hline \multicolumn{7}{|l|}{ Year } \\
\hline 2004 & $567(5.0)$ & $300(52.0)$ & $104(18.0)$ & 109 (18.9) & $9(1.6)$ & $45(7.8)$ \\
\hline 2005 & $212(3.0)$ & $103(47.7)$ & $24(11.1)$ & 68 (31.5) & $7(3.2)$ & $10(4.6)$ \\
\hline 2006 & $605(5.7)$ & $315(51.1)$ & $131(21.2)$ & $121(19.6)$ & $13(2.1)$ & $25(4.1)$ \\
\hline 2007 & 1049 (9.9) & $466(44.1)$ & 411 (38.9) & 114 (10.8) & $34(3.2)$ & $24(2.3)$ \\
\hline 2008 & $971(9.2)$ & 602 (61.6) & 106 (10.9) & $148(15.2)$ & $87(8.9)$ & $28(2.9)$ \\
\hline 2009 & 1296 (12.2) & 1077 (81.9) & $56(4.3)$ & $94(7.2)$ & $44(4.2)$ & $25(1.9)$ \\
\hline 2010 & 1353 (12.6) & 1191 (87.5) & $35(2.6)$ & $54(4.0)$ & $46(3.4)$ & $27(2.0)$ \\
\hline 2011 & 1289 (12.1) & 1139 (88.0) & $38(2.9)$ & $52(4.0)$ & $37(2.9)$ & $23(1.8)$ \\
\hline 2012 & 1147 (10.8) & 897 (77.9) & $34(3.0)$ & $62(5.4)$ & $136(11.8)$ & $18(1.6)$ \\
\hline 2013 & $1114(10.5)$ & $672(59.6)$ & $106(9.4)$ & $72(6.4)$ & 251 (22.3) & $13(1.2)$ \\
\hline 2014 & $998(9.4)$ & $503(50.1)$ & $157(15.6)$ & 244 (24.3) & $65(6.5)$ & $29(3.0)$ \\
\hline \multicolumn{7}{|l|}{ Quarter } \\
\hline 1 (Jan. - March) & 2403 (22.6) & $1684(69.4)$ & $256(10.55)$ & $267(11.0)$ & $143(5.9)$ & $53(2.2)$ \\
\hline 2 (April. - June) & $2549(24.0)$ & $1727(67.0)$ & $292(11.3)$ & 294 (11.4) & $171(6.6)$ & $65(2.5)$ \\
\hline 3 (July - Sept.) & 2848 (26.9) & $1920(67.1)$ & $353(12.3)$ & 301 (10.5) & $203(7.1)$ & $71(2.5)$ \\
\hline 4 (Nov. - Dec.) & $2812(26.5)$ & 1934 (68.3) & 301 (10.6) & $276(9.8)$ & 223 (7.9) & $78(2.8)$ \\
\hline \multicolumn{7}{|l|}{ Payment Type } \\
\hline 1 - Private & $5945(56.0)$ & 4074 (68.1) & $633(10.6)$ & 627 (10.5) & $431(7.2)$ & $180(3.0)$ \\
\hline 2 - Auto & $93(0.9)$ & 62 (66.7) & $10(10.8)$ & $10(10.8)$ & $7(7.5)$ & $4(4.3)$ \\
\hline 3 - Medical & 925 (8.7) & 631 (68.1) & 151 (16.3) & $83(9.0)$ & $42(4.5)$ & $18(1.9)$ \\
\hline \multicolumn{7}{|l|}{ Assistance } \\
\hline 4 - Medicare & 1456 (13.7) & 957 (63.9) & 159 (10.6) & $186(12.4)$ & $115(7.7)$ & $39(2.6)$ \\
\hline 5 - Workers & $123(1.2)$ & 77 (62.1) & 20 (16.1) & $18(14.5)$ & $8(6.5)$ & $0(0.0)$ \\
\hline \multicolumn{7}{|l|}{ Comp } \\
\hline 6 - Uninsured & 2097 (19.8) & $1464(70.0)$ & $229(11.0)$ & 214 (10.3) & 137 (6.6) & $26(1.3)$ \\
\hline
\end{tabular}


Table 2. Percentage of Oral or Dental Health ED Admission among individuals who did not have medical insurance at the Meadville Medical Center (2004-2014) by ICD-9 code classification.

\begin{tabular}{cccccc}
\hline & $\begin{array}{c}\text { Tooth \& Support } \\
\text { Structure Concerns }\end{array}$ & Dental Caries & Infection & $\begin{array}{c}\text { Unspecified Diseases } \\
\text { of the Soft Tissue }\end{array}$ & Injury \\
\hline Total Uninsured N (\%) & $1464(70.5)$ & $229(11.0)$ & $214(10.3)$ & $137(6.6)$ & $26(1.3)$ \\
Uninsured Ages 0 - 18 N (\%) & $64(4.4)$ & $6(2.6)$ & $11(5.1)$ & $6(4.4)$ & $6(23.1)$ \\
Uninsured Ages 19 - 38 N (\%) & $1228(83.9)$ & $184(80.35)$ & $158(73.8)$ & $103(75.18)$ & $17(65.4)$ \\
Uninsured Ages 39 - 58 N (\%) & $165(11.3)$ & $38(16.6)$ & $43(20.1)$ & $28(20.4)$ & $2(7.7)$ \\
Uninsured Age 59+ N (\%) & $7(0.5)$ & $1(0.4)$ & $2(0.9)$ & $0(0.0)$ & $1(3.9)$ \\
\hline
\end{tabular}

Table 3. Demographic characteristics of individuals admitted to the Meadville Medical Center ED using ICD-9 code 525.9 (2004-2014).

\begin{tabular}{|c|c|}
\hline Characteristics & ICD-9: $525.9 \mathrm{~N}(\%)^{*}$ \\
\hline \multicolumn{2}{|l|}{ Age } \\
\hline $0-18$ & 387 (5.6) \\
\hline $19-38$ & $5277(75.7)$ \\
\hline $39-58$ & $1180(17)$ \\
\hline $59+$ & 130 (1.9) \\
\hline \multicolumn{2}{|l|}{ Payment Type } \\
\hline Private & 3938 (56.5) \\
\hline Auto & $56(0.8)$ \\
\hline Medicaid & 595 (8.5) \\
\hline Medicare & $909(13.0)$ \\
\hline Workers Comp & $69(1.0)$ \\
\hline Uninsured & $1407(20.1)$ \\
\hline \multicolumn{2}{|l|}{ Year } \\
\hline 2004 & $224(2.1)$ \\
\hline 2005 & $72(0.67)$ \\
\hline 2006 & $291(2.7)$ \\
\hline 2007 & $44(0.41)$ \\
\hline 2008 & $577(5.4)$ \\
\hline 2009 & $1056(9.9)$ \\
\hline 2010 & $1166(11.0)$ \\
\hline 2011 & 1131 (10.6) \\
\hline 2012 & $891(8.3)$ \\
\hline 2013 & $659(6.2)$ \\
\hline 2014 & $463(4.6)$ \\
\hline
\end{tabular}

*For age and payment, percent reported is the percent of total admits for ICD-9 code 525.9. For year, percent reported is the percent out of total ED admits for 2004-2014. 
increasing. This study further supports previous studies that illustrate the use of EDs for dental and other oral health concerns are impacting clinical healthcare and public health services both locally and nationally [1]-[3] [10] [15]-[18].

Our data shows that the Meadville Medical Center ED is being used for more than just dental injuries. The majority of admissions were for structural and other preventable dental and other oral health concerns. The large number of ED admissions for dental and oral health concerns may be associated with the economic recession (both national and local), local public health policy, and access to care. Meadville is geographically isolated from easily accessible preventative dental health services; has increased rates of poverty; and has a growing elderly population [13] [14]. It is likely that income- and employment-related status, combined with economic stressors and decreased public health resources for adult dental coverage contributed to this trend [19] [20].

\subsection{National \& Local Trends}

The economic recession from 2007 to 2010 has led to higher unemployment rates as well as decreased rates of employer-based dental coverage [1]-[3] [10] [15]-[18]. Furthermore, with the increase in healthcare costs and the recent implementation of the Affordable Care Act (ACA), progress in controlling dental concerns has been paused. Under the ACA, dental coverage is only legally required for pediatric patients or those under the age of 19 years [21]. Without community interventions and adequate improvements in preventative dental health care for all, the trends of increased dental-related ED visits are likely to continue not just in Meadville but in the entire United States [22]-[24].

With the downturn of the national economy in the early 2000s and decreasing rates of dental insurance, it is possible that individuals chose to forego preventative dental health care. Individuals who lack dental, but have medical insurance may use the ED as their primary source of dental health care to avoid paying out of pocket for preventative dental health service [7] [22]. Statistics shows that economic barriers have decreased preventative/ routine dental care visits, and those living in poverty are the most likely to forego preventative care [9] [13]. Under these circumstances, it is no surprise that ED has become the avenue for dental treatment. With a decrease in preventative dental visits, it has become clear that dental diseases and associated poor oral health have manifested into a complicated epidemic of dental caries and structural issues, which are the most common admissions types in the ED [3] [4] [15]-[18] [23] [24].

Following the completion of a Community Health Needs Assessment in 2011, the Community Health Services Department of the Meadville Medical Center opened a dental clinic in Meadville [25]. This is the second dental health clinic open and serving the 88,000 residents of Crawford County. These clinics are inundated with individuals who are uninsured and underinsured. The three dentists in the Meadville Dental Clinic are seeing upwards of 600 patients each month [25]. Despite providing care to these patients; the rate of ED admissions for infections and dental caries has increased. This finding illustrates that providing access is. The amount of time spent on clinical care of patients at the dental clinic and in the ED is taking away from preventing dental caries and other preventable oral health concerns. Further research is needed to determine any associations between patients, services being offered and frequency compared to the ED.

With such frequency of dental concerns between the ED and other dental, it is important to address key areas that can improve one's oral health. In dental care, there is little time to address the upstream causes of the dental and oral health issues facing members of our community. One area that needs to be addressed by dentists in the Meadville community is water fluoridation. Currently, the community water supply provided by the Meadville Water Authority is not fluoridated. According the Centers for Disease Control and Prevention, community water fluoridation is the most affordable and effective prevention strategy under approved fluoride levels [26]. It is important to make the change to fluoridated water and promote proper oral health from a primary prevention stance.

\subsection{Strengths \& Limitations}

This study is the first of its kind in Pennsylvania, and it used a novel categorization of ICD-9 codes to dissect the ED admissions for dental and other oral health concerns in Meadville, PA. It is, however, difficult to get a correct interpretation of the frequency of repeat use of the ED without patient identification codes. Patient identification data was not available at the time of the study. We suspect that these 10,697 admissions did not result from 10,697 different individuals frequenting the ED. In fact, 8,259 of the 10,697 admissions are suspected to be 
from repeat customers. Repeats were assumed when two or more admissions had matching date of birth; sex; race; and insurance type. While this suggests there are frequent or repeat users of the ED, it cannot be concluded that each of these are the same individual. In addition, with de-identifiable admission data, treatment plans were not discussed nor was the acceptance rate of the prescribed treatment plan, limiting our understanding of ED dental and oral health concern admission. Since we only had access to de-identified records from the ED, we were unable to determine what treatment plans were prescribed in the ED or follow-up rates on these prescriptions.

\subsection{Conclusions}

Based on the high rates of ED admission for dental and oral health reasons, our study suggests the need for improved strategies and programs that emphasize dental prevention and aim to improve the oral health status throughout the community. Community support for improved community oral health has led to various oral health education programs including a Children's Dental Health Fair and efforts to add fluoride to the community water supply. Despite these efforts, there has been very little difference in the use of the ED for dental and other oral health concerns.

This study illustrates how our novel categorization of the ICD-9 codes allows for a more specific understanding of why the ED is being used for dental and other oral health concerns. Previous studies have only illustrated the general use of the ED, rather than a specific understanding of the different ICD-9 codes. Future research is needed to evaluate and improve community efforts, but should also incorporate a comprehensive understanding of the most frequently used dental and oral health related ICD-9 codes.

Further research is needed and important in order to evaluate the dental health status of the community over a longer period of time in order to evaluate the impact of the children's dental health fair; the types of services and care utilize at the dental health clinics; and the frequency of ED admissions. Such research will increase our knowledge and understanding of what policies, programs, and interventions are improving community oral health [1]-[4] [10]-[12] [15]-[18] [26].

With a large number of individuals in this community and the nation using the ED for dental and oral health concerns, it is necessary to reassess how dental healthcare services are provided and how they can better meet the needs of the population. While our study found that those aged 19 - 58 were the most frequent users of the ED, it was not the only population that needed preventative dental care at the community-level and dental health care education. Toothaches, dental caries and other oral health concerns impact all ages and greatly influence one's health status, illustrating the need for improved integration of dental and medical care [15] [21] [26]. The current situation nationally and locally solidifies the need to view oral health as an importance. In order to see improvements to community oral health, ending frequent ED use for toothaches and dental caries is essential. While the ED should be used for emergency use, it is not the adequate avenue for preventable dental health related concerns. Understanding and addressing barriers to oral health is essential on both the national and local level.

Finding solutions to this current problem will require dental, medical and public health professionals to work closely together in order to achieve short- and long-term goals. Increasing dental education to children, pregnant mothers, and the elderly as well as those living in poverty is just one example that can be used to address this problem. Increasing the number of dentists in the rural or free clinics may also allow for more opportunities to provide preventive care and education throughout the communities served. In conclusion, locally the Meadville Medical Center is leading the way to ensure such improvements to community oral health. Two new full-time and one part-time dentists have been hired at the clinic and the hospital is the lead organization advocating for fluoride to be added to the water. Nationally, we need to continue to advocate that dental and public health communities work together to reassess the ACA and establish sustainable programs and policies to improve oral health throughout each community.

\section{Acknowledgements}

We would like to thank our partners at the Meadville Medical Center, specifically Dr. Denise Johnson, Duane Koller, and Howard Minor. Additionally, we would like to thank the Allegheny College Global Health Research Team: Alyssa Brindle, Dan Favaro, David Lynn, Elizabeth Schafer, Ashley Weibel, Angelina Winbush, and Danielle Zehnder. This project was supported, in part, by a grant to Allegheny College from the Howard Hughes Medical Institute through the Precollege and Undergraduate Science Education Program, by funding from a 
grant awarded to support Allegheny College's Community Wellness Initiative, and a grant awarded by the Franklin H. and Ruth L. Wells Foundation to support the CHNA work conducted by Allegheny College students under the direction of Professor Rebecca Smullin Dawson.

\section{References}

[1] DeLia, D., Lloyd, K., Feldman, C.A. and Cantor, J.C. (2015) Patterns of Emergency Department Use for Dental and Oral Health Care: Implications for Dental and Medical Care Coordination. Journal of Public Health Dentistry. http://onlinelibrary.wiley.com/doi/10.1111/jphd.12103/abstract

[2] Allareddy, V., Rampa, S., Lee, M.K. and Nalliah, RP. (2014) Hospital-Based Emergency Department Visits Involving Dental Conditions: Profile and Predictors of Poor Outcomes and Resource Utilization. The Journal of the American Dental Association, 145, 331-337. http://www.sciencedirect.com/science/article/pii/S0002817714600106 http://dx.doi.org/10.14219/jada.2014.7

[3] McCormick, A.P., Abubaker, A.O., Laskin, D.M., Gonzales, M.S. and Garland, S. (2013) Reducing the Burden of Dental Patients on the Busy Hospital Emergency Department. Journal of Oral and Maxillofacial Surgery, 71, 475-478. http://www.sciencedirect.com/science/article/pii/S0278239112012335 http://dx.doi.org/10.1016/j.joms.2012.08.023

[4] McKinney, L. and Lee, M.R. (2015) Visits to US Emergency Departments by 20- to 29-Year-Olds with Toothache during 2001-2010. The Journal of the American Dental Association, 146, 302.e2.

[5] Action for Dental Health. From the Emergency Room to the Dental Chair. American Dental Association Web Site. http://www.ada.org/en/public-programs/action-for-dental-health/er-referral?source=facebook\&content=ADH_ER_1

[6] (2013) Action for Dental Health: Bringing Disease Prevention into Communities. American Dental Association.

[7] Wall, T., Nasseh, K. and Vujicic, M. (2014) Majority of Dental-Related Emergency Department Visits LACK Urgency and Can Be Diverted to Dental Office. American Dental Association Health Policy Institute. http://www.ada.org/ /media/ADA/Science\%20and\%20Research/HPI/Files/HPIBrief_0814_1.ashx

[8] Wall, T. and Nasseh, K. (2013) Emergency Department Use for Dental Conditions Continues to Increase. American Dental Association Health Policy Institute. http://www.ada.org/ /media/ADA/Science\%20and\%20Research/HPI/Files/HPIBrief_0513_1.ashx

[9] Seu, K., Hall, K. and Moy, E. (2012) Emergency Department Visits for Dental Related Conditions, 2009 Agency for Healthcare Research and Quality, Healthcare Cost and Utilization Project (HCUP) Statistical Brief \#143. http://www.ncbi.nlm.nih.gov/books/NBK116745/pdf/Bookshelf_NBK116745.pdf

[10] Shortridge, M. (2009) Use of Emergency Departments for Conditions Related to Poor Oral Healthcare: Implications for Rural and Low-Resource Urban Areas for Three States. Journal of Public Health Management and Practice, 15, 238-245. http://content.wkhealth.com/linkback/openurl?sid=WKPTLP:landingpage\&an=00124784-200905000-00010 http://dx.doi.org/10.1097/PHH.0b013e3181a1179f

[11] WHO (2013) Oral Health Surveys Basic Methods. World Health Organization, 1-125.

[12] Skillman, S.M., Doescher, M.P., Mouradian, W.E. and Brunson, D.K. (2010) The Challenge to Delivering Oral Health Services in Rural America. Journal of Public Health Dentistry, 70, S49-S57. http://onlinelibrary.wiley.com/doi/10.1111/j.1752-7325.2010.00178.x/full http://dx.doi.org/10.1111/j.1752-7325.2010.00178.x

[13] (Accessed 9 July 2015) Crawford County Pennsylvania QuickFacts from the US Census Bureau. United States Census Bureau Web Site. http://factfinder.census.gov/faces/tableservices/jsf/pages/productview.xhtml?src=bkmk

[14] (Accessed 9 July 2015) Meadville (city) Pennsylvania QuickFacts from the US Census Bureau. United States Census Bureau Web Site. http://quickfacts.census.gov/qfd/states/42/4248360.html

[15] Vanderbilt, A.A., Isringhausen, K.T., VanderWielen, L.M., Wright, M.S., Slashcheva, L.D. and Madden, M.A. (2013) Health Disparities among Highly Vulnerable Populations in the United States: A Call to Action for Medical and Oral Health Care. Medical Education Online, 18, Article ID: 20644. http://www.med-ed-online.net/index.php/meo/article/view/20644 http://dx.doi.org/10.3402/meo.v18i0.20644

[16] Jones, E., Shi, L.Y., Hayashi, A.S., Sharma, R., Daly, C. and Ngo-Metzger, Q. (2013) Access to Oral Health Care: The Role of Federally Qualified Health Centers in Addressing Disparities and Expanding Access. American Journal of Public Health, 103, 488-493. http://ajph.aphapublications.org/doi/abs/10.2105/AJPH.2012.300846 http://dx.doi.org/10.2105/AJPH.2012.300846

[17] Kenney, G.M., McFeeters, J.R. and Yee, J.Y. (2005) Preventive Dental Care and Unmet Dental Needs among LowIncome Children. American Journal of Public Health, 95, 1360-1366. 
http://ajph.aphapublications.org/doi/abs/10.2105/AJPH.2004.056523 http://dx.doi.org/10.2105/AJPH.2004.056523

[18] Dye, B., Thornton-Evans, G., Li, X. and Lafolla, T. (2015) Dental Caries and Tooth Loss in adults in the United States, 2011-2012. Centers of Disease Control and Prevention: National Center for Health Statistics, No. 197, 1-8. http://www.cdc.gov/nchs/data/databriefs/db197.pdf

[19] Vujicic, M., Yarbrough, C. and Nasseh, K. (2014) The Effect of the Affordable Care Act’s Expanded Coverage Policy on Access to Dental Care. Medical Care, 52, 715-719.

http://content.wkhealth.com/linkback/openurl?sid=WKPTLP:landingpage\&an=00005650-201408000-00007 http://dx.doi.org/10.1097/MLR.0000000000000168

[20] (2010) One Hundred Eleventh Congress of the United Stated of America. Patient Protection and Affordable Care Act. http://www.gpo.gov/fdsys/pkg/BILLS-111hr3590enr/pdf/BILLS-111hr3590enr.pdf

[21] Cook, A.A. (7 July 2015) Dental ER Visits Draw Advice from Groups. The Courier-Journal. http://www.courier-journal.com/story/opinion/readers/2015/07/07/letters-dental-er-visits-draw-advice-groups/2980769 5/

[22] (2010) America’s Oral Health: The Role of Dental Benefits. Delta Dental Insurance.

[23] United States Department of Health and Human Services (Accessed 20 July 2015) The Affordable Car Act and Health Centers Health Resources and Services Administration Web site. http://bphc.hrsa.gov/about/healthcenterfactsheet.pdf

[24] (Accessed 20 July 2015) Healthy People 2020: Oral Health Objectives. Office of Disease Prevention and Health Promotion Web Site. http://www.healthypeople.gov/2020/topics-objectives/topic/oral-health/objectives

[25] (Accessed 11 July 2015) Community Health Services: Meadville Dental Center. Meadville Medical Center Web Site. http://www.MeadvilleMedicalCenterhs.org/Services/CommunityHealthServices/FamilyPlanningServices/DentalCenter s/MeadvilleDentalCenter.aspx

[26] Jasek, J.P., Hosseinipour, N., Rubin, T. and Lall, R. (2013) Using Syndromic Emergency Department Data to Augment Oral Health Surveillance. Online Journal of Public Health Informatics, 5.

http://journals.uic.edu/ojs/index.php/ojphi/article/view/4407 http://dx.doi.org/10.5210/ojphi.v5i1.4407 